\title{
THE ATLANTIC MERIDIONAL OVERTURNING CIRCULATION IS NOT COLLAPSING
}

\author{
Albert Parker (i] ${ }^{1}$, ClifFord Ollier (i]) ${ }^{2}$ \\ ${ }^{1}$ Prince Mohammad Bin Fahd University, Khobar, Saudi Arabia \\ ${ }^{2}$ The University of Western Australia, Perth, Australia \\ Manuscript received: August 9, 2021 \\ Revised version: August 29, 2021
}

Parker A., Ollier C., 2021. The Atlantic Meridional Overturning Circulation is not collapsing. Quaestiones Geographicae 40(3), Bogucki Wydawnictwo Naukowe, Poznań, pp. 163-167. 1 fig.

Abstract: The authors discuss the Boers (2021) view on the nature of the circulation of the Atlantic Meridional Overturning Circulation (AMOC).

KEY WORDS: Atlantic Meridional Overturning Circulation

Corresponding author: Albert Parker: albert.parker.2014@gmail.com

Boers (2021) wrote that, in the last century, the Atlantic Meridional Overturning Circulation (AMOC) may have evolved from relatively stable conditions to a point close to a critical transition. The claim is based on different AMOC indices, based on observational sea-surface temperature and salinity data from across the Atlantic Ocean basin. Boers' conclusions (2021) are not based on systematic observations spanning the last and this century, but on subjective reconstructions of sea surface temperature and salinity, as accurate sea-surface and temperature data are only available over the last few decades. Additionally, the AMOC strength does not only correlate to sea surface temperature and salinity data. His assumption that the strength of the AMOC depends on poorly described sea-surface temperature and salinity only is not substantiated. The difficulties of estimating the sea surface temperature (SST) are highlighted in Chan et al. (2019). Even more difficult are the estimations of salinity.

While many studies mostly computational present similar alarmist views, Boers ignores the many other studies which are more related to experiments that support the view that the AMOC has been stable for 150 years, such as Parker (2016), Parker, Ollier (2016, 2019). These other works propose an alternative view based on many more factors including real observation of sea surface height (SSH) and ocean temperature, salinity, and velocity, as well as the difference between the absolute mean sea levels (MSL) of the tide gauges of The Battery, New York, and Brest, available since 1856. As shown in Parker, Ollier (2016), using all these factors, AMOC strength:

1 . has been minimally reducing but with a positive acceleration since 2002,

2. has been marginally increasing but with a negative acceleration since 1993, and

3. has not been reducing but only oscillating with periodicities up 18 years, 27 years and about 60 years since 1856 .

Nothing has changed since Parker, Ollier's paper (2016). Figure 1a presents the AMOC SSH and ARGO and the AMOC SSH only. The ARGO measurements are only available since 2002. Since then, the AMOC SSH and ARGO are reducing (negative first-order coefficient of the 
a

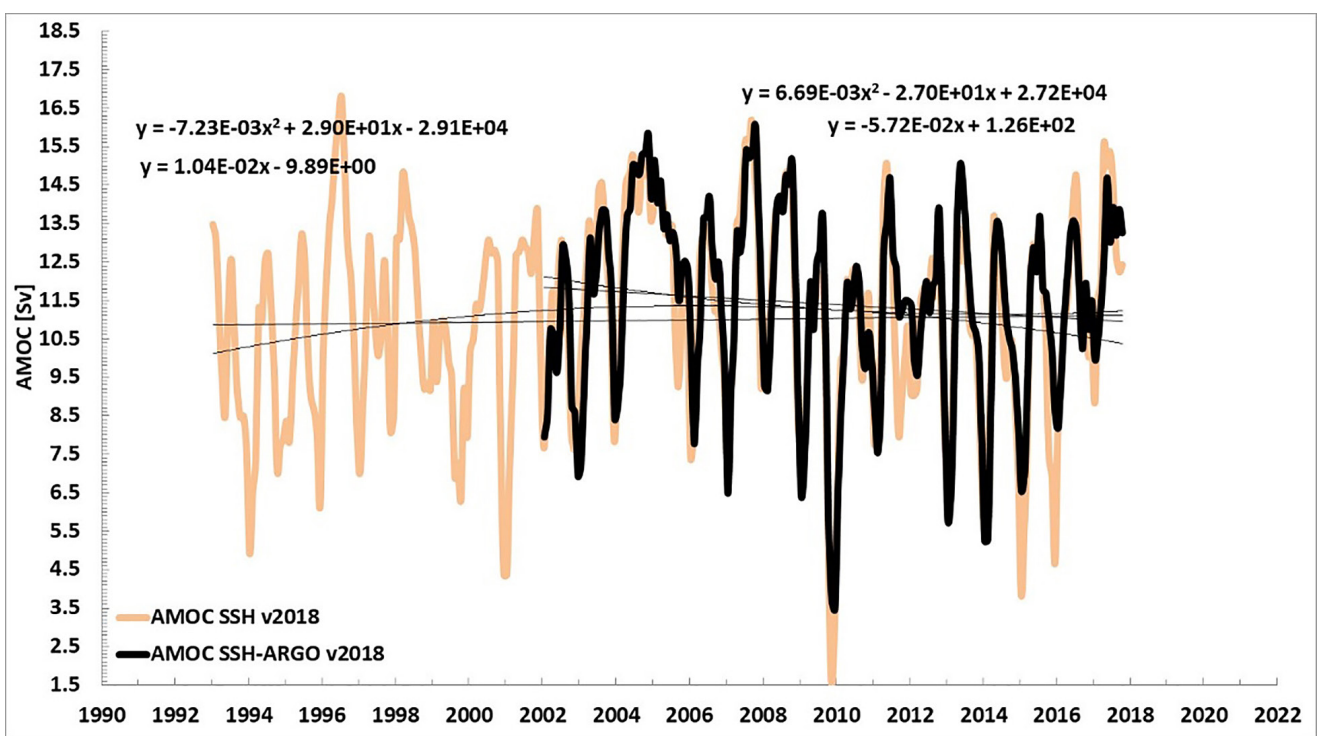

b

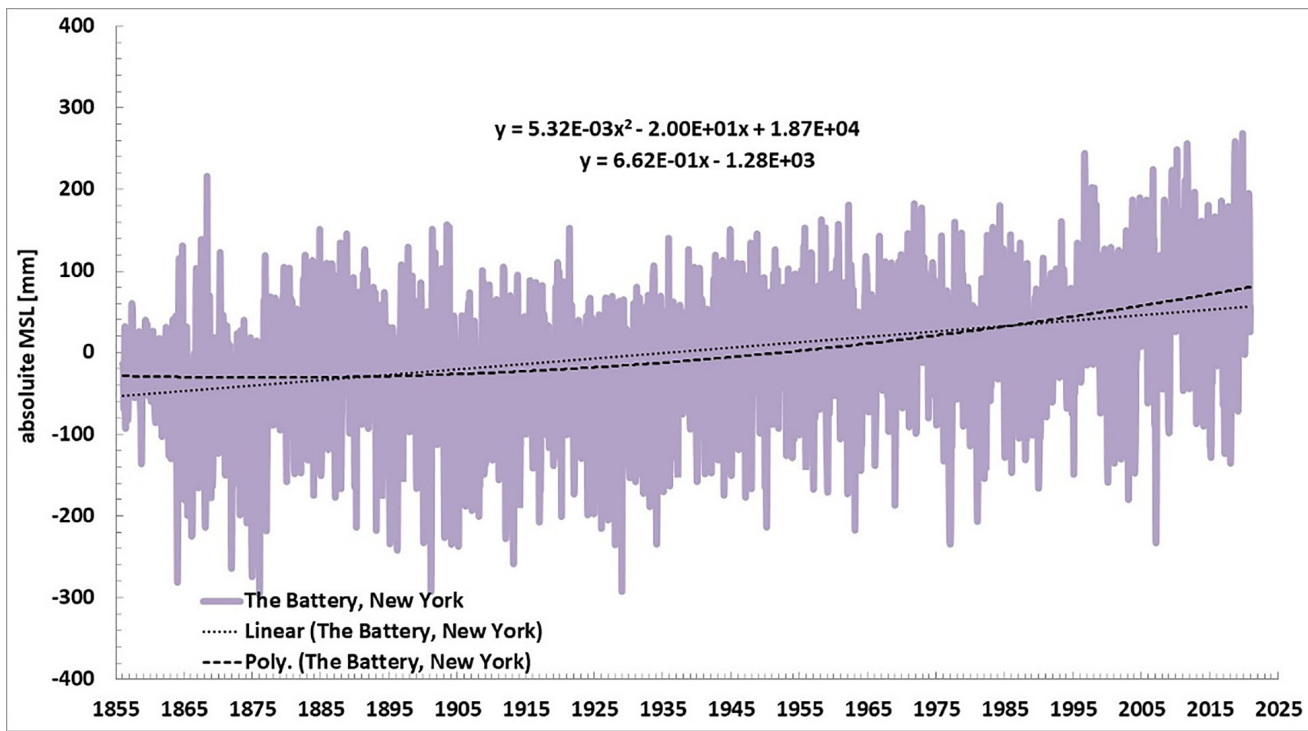

C

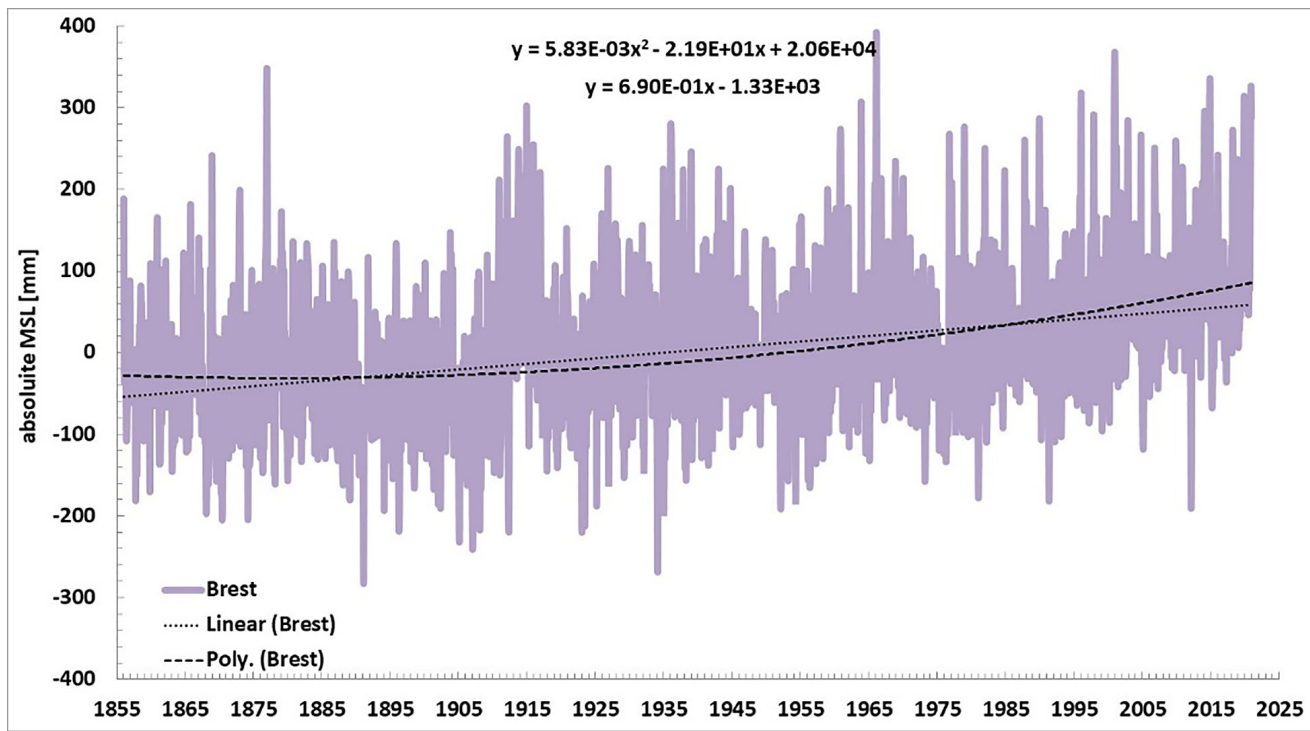

Fig. 1. (a) AMOC SSH and SSH and ARGO. (b) and (c) absolute monthly average mean sea level in The Battery, New York, and Brest. 
d

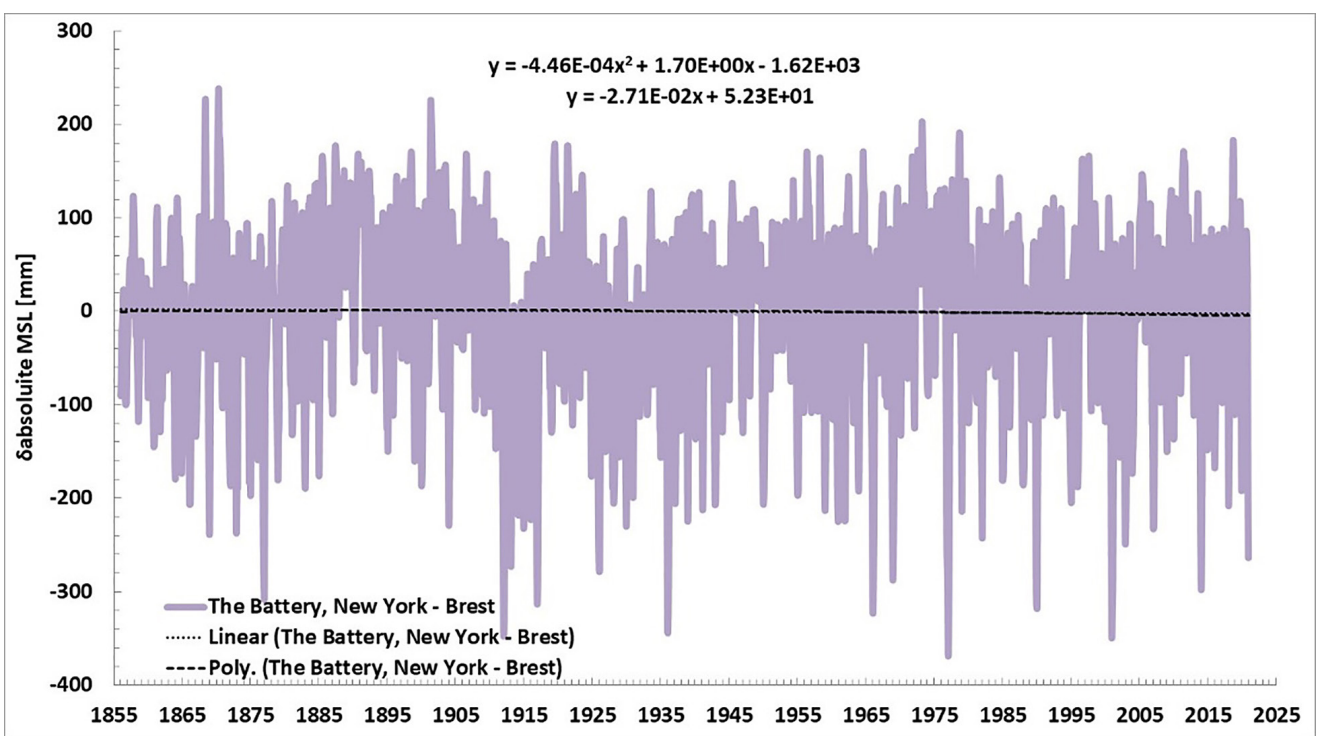

e

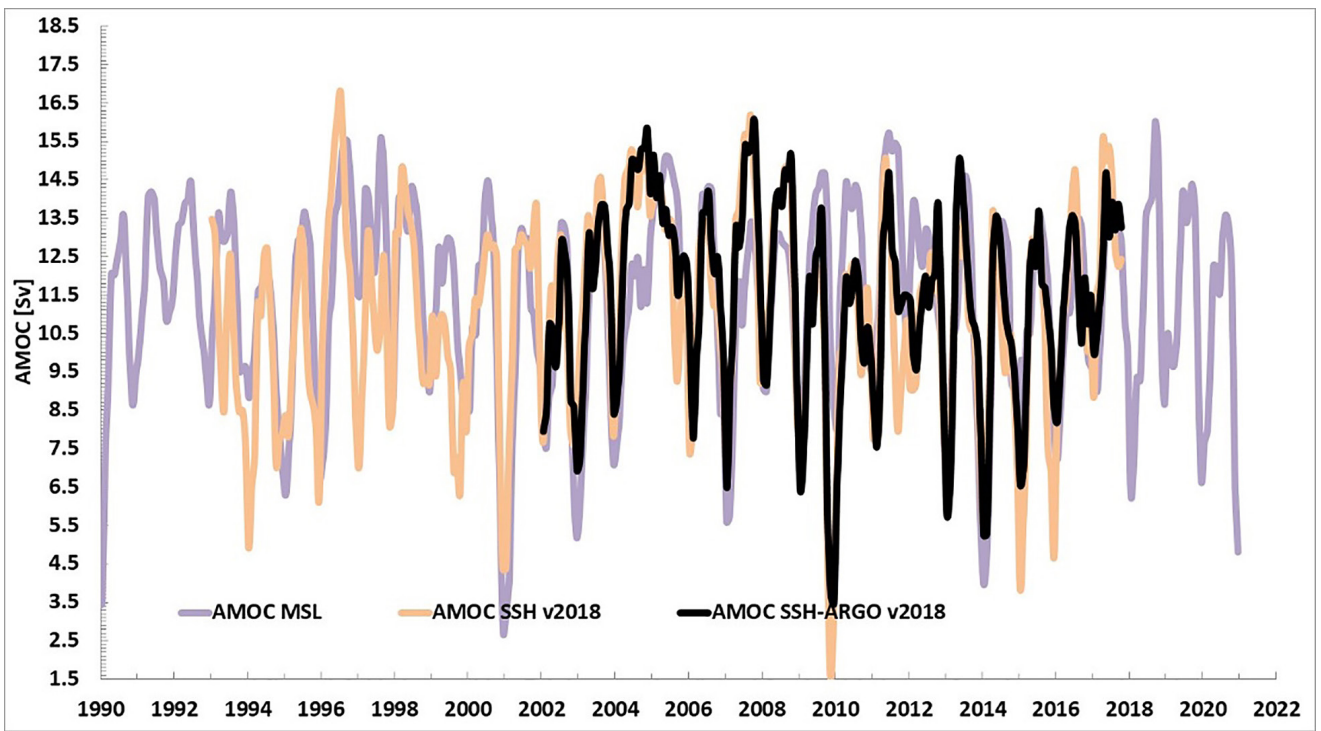

$f$

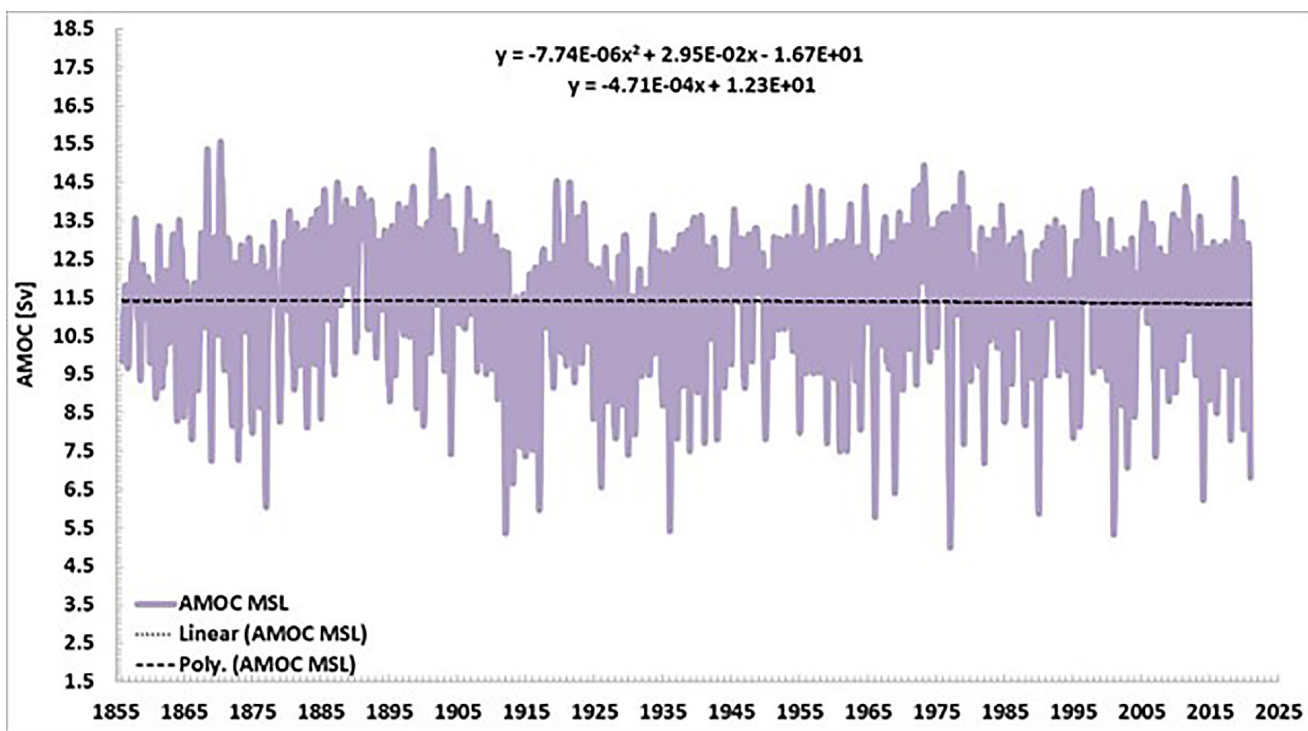

Fig. 1. (d) Difference between New York and Brest. (e) AMOC MSL, AMOC SSH v2018 and AMOC SSH-ARGO v 2018 compared. (f) AMOC MSL since 1856.

AMOC - Atlantic Meridional Overturning Circulation; MSL - mean sea level; SSH - sea surface height. 
linear fitting) but with a positive acceleration (positive second-order coefficient of the parabolic fitting). The SSH measurements are available since 1993. Since then, the AMOC SSH is increasing (positive first-order coefficient of the linear fitting) but with a negative acceleration (negative second-order coefficient of the parabolic fitting). From 2002 to 2018, the AMOC SSH and the AMOC SSH and ARGO are close to each other.

This image tells us it makes no sense to play with short records when dealing with phenomena that are characterised by very well-known decadal and multi-decadal oscillations (Schlesinger, Ramankutty 1994, Minobe 1997, Knudsen et al. 2011, Chambers et al. 2012, Mazzarella, Scafetta 2012). A short window of 10, 20 or 30 years is inadequate to infer a trend.

If the AMOC accelerates or decelerates, this should be detected at the tide gauges located on the opposite sides of the Atlantic. As shown in Figures $1 \mathrm{~b}$ and $1 \mathrm{c}$, the absolute sea levels measured in The Battery, New York, and Brest since 1856 have a very similar pattern. Once a constant subsidence rate is subtracted from the relative mean sea level time series, the linear and parabolic fittings return very close velocities and very close accelerations. If we make the difference between the absolute sea levels of The Battery, New York, and Brest, this time series is characterised by a very small velocity, and a very small acceleration, demonstrating significant stability since 1856. An AMOC monthly average mean sea levels (MSL) can be made linearly dependent on the absolute sea-level difference between The Battery, New York, and Brest (Fig. $1 \mathrm{~d}$ and e). This AMOC correlates well with the other two during the period of common observation. Since 1856, the AMOC MSL has had linear and parabolic fittings characterised by a very small velocity and very small acceleration.

In the midst of the many other works that have shown that major oceanic circulations have not slowed, as suggested by Boers (2021). Hu et. al. (2020) showed a statistically significant increasing trend in the globally integrated oceanic kinetic energy since the early 1990s, which is consistent with the AMOC SSH trend of Figure 1. We must mention also the difficulties of showing ocean velocity changes as discussed by Wunsch (2020) in the context of $\mathrm{Hu}$ et al. (2020). On a longer time frame, other studies such as Rossby et al. (2014) also concluded that large-scale ocean currents are perfectly stable, which is consistent with the AMOC MSL of Figure 1 and the MSL results of The Battery and Brest.

So, Boers (2021) may claim that there are signs of deceleration since the last century, based on his subjective reconstructions using only inaccurate sea surface temperature and salinity. We maintain that the AMOC is stable, based on analysis of many more factors and more reliable data. The Boers narrative (2021) is not accurate, as much readily available material is omitted and alternative interpretations are not discussed. While we can expect further scare stories of the Gulf Stream in the future, from a scientific perspective, there is no reason to worry about a slowing down. Based on objective parameters, it is more likely stable than decelerating.

\section{Acknowledgements}

The authors wish to thank the two reviewers for their comments and suggestions.

\section{References}

Boers N., 2021. Observation-based early-warning signals for a collapse of the Atlantic Meridional Overturning Circulation. Nature Climate Change 11: 680-688. DOI 10.1038/ s41558-021-01097-4.

Chambers D.P., Merrifield M.A., Nerem R.S., 2012. Is there a 60-year oscillation in global mean sea level?. Geophysical Research Letters 39(18). DOI 10.1029/2012GL052885.

Chan D., Kent E.C., Berry D.I., Huybers P., 2019. Correcting datasets leads to more homogeneous early-twentieth-century sea surface warming. Nature 571(7765): 393-397. DOI 10.1038/s41586-019-1349-2.

Hu S., Sprintall, J., Guan C., McPhaden M.J., Wang F., Hu D., Cai W., 2020. Deep-reaching acceleration of global mean ocean circulation over the past two decades. Science Advances 6(6): eaax7727. DOI 10.1126/sciadv.aax7727.

Knudsen M.F., Seidenkrantz M.S., Jacobsen B.H., Kuijpers A., 2011. Tracking the Atlantic Multidecadal Oscillation through the last 8,000 years. Nature Communication 2(1): 1-8. DOI 10.1038/ncomms1186.

Mazzarella A., Scafetta N., 2012. Evidences for a quasi 60-year North Atlantic Oscillation since 1700 and its meaning for global climate change. Theoretical and Applied Climatology 107(3-4): 599-609. DOI 10.1007/s00704-011-0499-4.

Minobe S., 1997. A 50-70 year climatic oscillation over the North Pacific and North America. Geophysical Research Letters 24(6): 683-686. DOI 10.1029/97GL00504.

Parker A., 2016. Atlantic Meridional Overturning Circulation is stable under global warming. Proceedings of the National Academy of Sciences 113(20): E2760-E2761. DOI 10.1073/ pnas.1604187113. 
Parker A., Ollier C., 2019. Atlantic Meridional Overturning Circulation stable over the last 150 years. Quaestiones Geographicae 38(3): 31-40. DOI 10.2478/quageo-2019-0026.

Parker A., Ollier C.D., 2016. There is no real evidence for a diminishing trend of the Atlantic Meridional Overturning Circulation. Journal of Ocean Engineering and Science 1(1): 30-35. DOI 10.1016/j.joes.2015.12.007.

Rossby T., Flagg C.N., Donohue K., Sanchez-Franks, A., Lillibridge J., 2014. On the long-term stability of Gulf
Stream transport based on 20 years of direct measurements. Geophysical Research Letters 41(1): 114-120. DOI 10.1002/2013GL058636.

Schlesinger M.E., Ramankutty N., 1994. An oscillation in the global climate system of period $65-70$ years. Nature 367(6465): 723-726. DOI 10.1038/367723a0.

Wunsch C., 2020. Is the ocean speeding up? Ocean surface energy trends. Journal of Physical Oceanography 50(11): 3205-3217. DOI 10.1175/JPO-D-20-0082.1. 